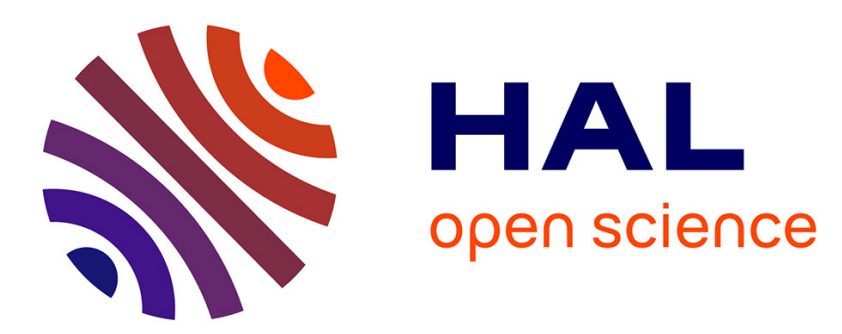

\title{
One-Step Hydrothermal Synthesis of Nitrogen-Doped Nanocarbons: Albumine Directing the Carbonization of Glucose.
}

Niki Baccile, M. Antonietti, M.-M. Titirici

\section{- To cite this version:}

Niki Baccile, M. Antonietti, M.-M. Titirici. One-Step Hydrothermal Synthesis of Nitrogen-Doped Nanocarbons: Albumine Directing the Carbonization of Glucose.. ChemSusChem, 2009, 3 (2), pp.246253. 10.1002/cssc.200900124 . hal-00429908

\section{HAL Id: hal-00429908 https://hal.science/hal-00429908}

Submitted on 3 Feb 2017

HAL is a multi-disciplinary open access archive for the deposit and dissemination of scientific research documents, whether they are published or not. The documents may come from teaching and research institutions in France or abroad, or from public or private research centers.
L'archive ouverte pluridisciplinaire HAL, est destinée au dépôt et à la diffusion de documents scientifiques de niveau recherche, publiés ou non, émanant des établissements d'enseignement et de recherche français ou étrangers, des laboratoires publics ou privés. 


\title{
One-step Hydrothermal Synthesis of Nitrogen- Doped Nanocarbons: Albumine Directing the Carbonization of Glucose
}

\author{
Niki Baccile ${ }^{[b]}$, Markus Antonietti ${ }^{[a]}$ and Maria-Magdalena Titirici ${ }^{[a] *}$
}

In this work, we present a simple and green one-step pathway towards nitrogen-doped carbon nanostructures with controlled mesoporosity via hydrothermal treatment of glucose in the presence of model proteins. Thus, performing the reaction with different amounts of egg white ovalbumin protein (OvA), carbonaceous nanoparticles or continuous nanosponges with high specific surface areas can be efficiently produced. The nitrogen content of the structures is rather high (up to 8 wt\%) and can be kept constant up to

\section{Introduction}

Carbon-based materials with large surface area or small particle size are made along a number of different synthesis pathways. ${ }^{[1-4]}$ Activated carbons are generally synthesized from raw biomass but the conditions are usually very harsh, involving high temperatures $\left(600-900^{\circ} \mathrm{C}\right)$ and pressures under oxidizing atmospheres $\left(\mathrm{O}_{2}, \mathrm{CO}_{2}\right.$, steam) or chemical treatment with acids (e.g., phosphoric acid), bases (e.g., $\mathrm{KOH}, \mathrm{NaOH})$ or salts $\left(\mathrm{ZnCl}_{2}\right)$. Recently, much softer condensation routes to obtain periodic porous carbon networks ${ }^{[5-8]}$ were presented. From a cost, processing and sustainability perspective, there is however still space for improvements, as indirect impregnation techniques with mesoporous silica as a template, hydrogen fluoride etching, ${ }^{[5,8]}$ and finally high carbonization temperature ${ }^{[5]}$ are required. Direct templating of resins (phenol/formaldehyde) ${ }^{[6]}$ is presumably most promising, but restricted to a distinct monomer polarity and functionality and excludes the use of natural products as carbon source.

Energy and sustainability issues are even less well covered in case of nanosized forms of carbon, ranging from nanoparticulate soots and fullerenes to nanotubes. Their synthesis is performed using energy-consuming methods like arc discharge, laser ablation or Chemical Vapor Deposition (CVD), ${ }^{[3]}$ $950^{\circ} \mathrm{C}$, while oxygen elimination and graphitization of the carbon material occurs. We demonstrate here that sustainable natural resources can be efficiently used in the synthesis of pure highpotential nanomaterials.

whereas printing soots are still made by incomplete combustion of natural gas, being an element and energy inefficient process..$^{[9}$, 10] Recently, an electrochemical method was developed to produce carbon nano colloids, ${ }^{[11]}$ and carbon nanoparticles with interesting fluorescence ${ }^{[12]}$ and anti-microbial[13] properties from candle soot were presented, underlining the increasing interest towards more sustainable processing approaches to carbon nanostructures.

According to our opinion and excluding activated carbons, only little research has been done to synthesize and recognize the structure of carbon materials based on natural resources. This is hard to understand, as carbon structure synthesis was

[a] Dr. Maria-Magdalena Titirici-corresponding author, Prof Dr. Markus Antonietti

Colloid Chemistry

Max-Planck Institute for Colloids and Interfaces

Am Muhlenberg 1, 14476, Potsdam, Germany

E-mail: Magdalena.Titirici@mpikg.mpg.de

[b] Dr. Niki Baccile

UPMC Univ. Paris 06, UMR 7574

Chimie de la Matière Condensée de Paris,

F-75005, Paris, France

Supporting information for this article is available on the WWW under http://www.chemsuschem.org or from the author 
done from the beginning of civilization on the base of biomass, with the petrochemical age being a late deviation, only. A modern approach towards carbon synthesis based on renewable resources is a significant operation, as the final products represent an important share of materials of the next generation. They already have found applications in different domains ranging from environmental science ${ }^{[14-16]}$ to drug delivery ${ }^{[17-19]}$ and energy storage ${ }^{[20]}$ depending on their structural, morphological and chemical properties. ${ }^{[21]}$ Synthesizing materials using sustainable approaches is definitely not new but currently revamped for the field of nanomaterials, as shown by recent review papers. ${ }^{[22-24]}$

Another issue which has to be addressed in a novel carbon synthesis is functionalization, which is required in most specific applications. ${ }^{[25-29]}$ For instance, fuel cell development has turned its attention towards nitrogen-doped carbon nanostructures, as these materials seem to enhance the catalytic activity towards oxygen reduction reactions in fuel cell electrodes. ${ }^{[30]}$ In addition, $\mathrm{N}$-doped carbons are also interesting as $\mathrm{CO}_{2}$ binders ${ }^{[31]}$ or $\mathrm{pH}-$ responsive adsorbents. ${ }^{[32]}$

The problem of the sustainable synthesis in functional carbons was recently revisited by several research groups, ${ }^{[33-39]}$ where hydrothermal treatment of biomass in water under relatively mild conditions and, in some cases, in presence of additives provided mesoporous or nanostructured carbon materials. ${ }^{[40-55]}$ This technique is known for many years, ${ }^{[56]}$ but the forthcoming raw material change made a re-discovery of this technique timely. In addition, the implementation of a low-cost pathway to recycle byproducts of farmed biomass would represent a way to sequester significant amounts of $\mathrm{CO}_{2}{ }^{[37]}$ in carbon negative products, creating a materials benefit at the same time.

The use of hydrothermal synthesis between $180^{\circ} \mathrm{C}$ and $220^{\circ} \mathrm{C}$ allowed to obtain carbon-based powders, nanofibers ${ }^{[57,58]}$, or sponge-like mesoporous carbons being potentially useful as soil conditioner, ion exchange resins or sorption coals. ${ }^{[36]}$ The synthesis proved to be feasible both for simple systems as glucose ${ }^{[38]}$ and for raw biomass side products, such as oak leafs and orange peals. ${ }^{[36]}$ In the first case, surface chemistry could also be modified by mean of hydrophilic or hydrophobic postfunctionalization. ${ }^{[59]}$ Along similar lines, the group of Clark showed that a slightly different approach using expanded starch treated with sulfuric acid could provide functional materials with disordered mesoporosity which proved to be satisfactory catalysts in the esterification of succinic acid. ${ }^{[43,60]}$

In these experiments, it was found that some crude biomass mixtures created carbons with exciting nanostructures, ${ }^{[36]}$ however bound to the specific biomass with its potentially regional and seasonal fluctuations. It was speculated that this development of nanostructure was due to natural surface stabilizers contained in the biomass, such as tannins and lipids, but also the presence of small amounts of amines and proteins seemed to have a crucial influence. This is why we study in this paper the carbon nanostructures obtained upon hydrothermal carbonization of a mixture of a simple and accessible model protein, ovalbumin (OvA, chicken egg white) and pure glucose as a model carbohydrate. At the same time, we will answer the question whether we are able to introduce the highly attractive nitrogen functionality into the condensed carbon black just by using higher protein loads and co-condensation (formation of "nitrogen blacks"). It will be shown that it is possible to create carbon nanoparticles and inter grown nanostructures with structural sizes between 10 and $50 \mathrm{~nm}$ rich in nitrogen just by reacting glucose with ovalbumin as co-reactant under hydrothermal conditions.

\section{Results and Discussion}

\section{Characterization of the Hydrothermal Carbons (HC)}

Figure 1 shows SEM micrographs of the final carbon materials obtained after hydrothermal treatment of glucose in presence of different concentrations of OVA. It can be observed that all materials exhibit a continuous nanometer-scale sponge-like network structure made up from primary particles ranging between $10-40 \mathrm{~nm}$. Not all the formed droplets are spherical, but cylindrical tectons are also present, indicating a rather low interface tension in the liquid phases of the reaction.

Figure 1. SEM images for samples HC-AlbX, X=1, 2, 4.

TEM images shown in Figure 2 at lower $(a, b)$ and higher magnification (c, d) nicely confirm SEM data. In sample HC-Alb2, the primary network constituting particles are found to be in the nano-range, between 20 and $50 \mathrm{~nm}$, while HC-Alb1 (the sample with the lowest OvA concentration) shows the existence of more interconnected filaments or particles whose size is bigger and in the order of $70-100 \mathrm{~nm}$. It is indeed remarkable that with increasing OvA content, the carbon structure changes from a micron-sized carbon dispersion to a much finer, cohesive spongelike structure. We assume that OvA (through its reaction and condensation products) indeed stabilizes the surface of much smaller nanoparticles, which throughout the course of reaction turned out to be unstable and to aggregate towards linked networks, however without pronounced coalescence. Aggregation is a common phenomenon in carbon colloids, ${ }^{[61]}$ as the mutual particle-particle interactions are quite strong, and is observed in all our samples as well.
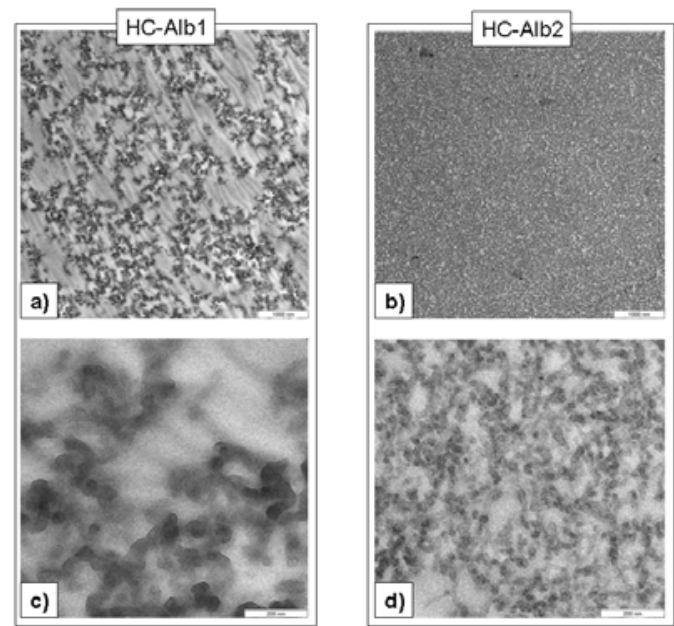

Figure 2. TEM images of HC-Alb1 and HC-Alb2. Scale bars is $1000 \mathrm{~nm}$ in (a, b) and $200 \mathrm{~nm}$ in (c, d). 
Nitrogen adsorption-desorption isotherms allow to quantify the character of the interstitial porous system and were performed for all HC-AlbX bulk materials (Figure $3 \mathrm{a}$ ). The presence of both the surface areas and hysteresis loop at $\mathrm{P} / \mathrm{P}_{0}$ values lower than 1 for most samples indicate the clear existence of a mesoporous network, whose origin can only come from the inter-particle architecture. Surface areas ranging between 30 and $110 \mathrm{~m}^{2} / \mathrm{g}$ (Table 1) as well as the mesopore sizes between 10 and $40 \mathrm{~nm}$ are in good agreement with the morphologies depicted in the electron micrographs presented before. We can exclude intraparticle porosity for the as-synthesized hydrothermal samples, as this is not observed by TEM and nitrogen adsorption experiments. Such a value based on sole mesoporosity is actually among the highest reported in literature for as-synthesized hydrothermal carbons $(\mathrm{HC})$. The $\mathrm{BJH}$ pore size distribution for selected samples in the middle of the composition range (Figure $3 \mathrm{~b}$, open circles) is relatively sharp and centered at about $20 \mathrm{~nm}$.
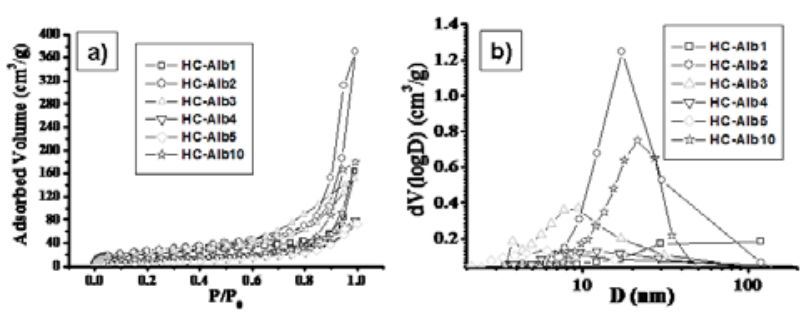

Figure 3. - a) Nitrogen adsorption-desorption isotherms and b) $\mathrm{BJH}$ pore size distribution curves for samples HC-AlbX $(X=1-10)$.

\begin{tabular}{|c|c|c|c|c|c|}
\hline Material & BET & $\mathrm{S}\left(\mathrm{m}^{2} / \mathrm{g}\right)$ & $\mathrm{N}[\% \mathrm{w}]$ & $\mathrm{C}[\% \mathrm{w}]$ & $\mathrm{N} / \mathrm{C}$ \\
\hline HC-Alb1 & 83 & 74 & 3.1 & 67.0 & 21.7 \\
\hline HC-Alb1-350 & 100 & 100.4 & 3.2 & 67.8 & 20.9 \\
\hline HC-Alb1-550 & 397 & 397.6 & 3.6 & 86.4 & 23.8 \\
\hline HC-Alb1-750 & 381 & 381.4 & 3.1 & 84.9 & 27.5 \\
\hline HC-Alb1-950 & 255 & 358.4 & 2.5 & 89.1 & 36.1 \\
\hline HC-Alb2 & 99 & 112 & 4.9 & 67.6 & 13.7 \\
\hline HC-Alb2-350 & 106 & 106.6 & 4.8 & 71.3 & 15.0 \\
\hline HC-Alb2-550 & 359 & 359.3 & 4.8 & 82.2 & 17.0 \\
\hline HC-Alb2-750 & 246 & 246.1 & 4.1 & 83.4 & 20.3 \\
\hline HC-Alb2-950 & 152 & 152.1 & 3.2 & 87.3 & 27.2 \\
\hline HC-Alb3 & 41 & 81 & 5.4 & 65.8 & 12.3 \\
\hline HC-Alb3-350 & 50 & 89.9 & 5.9 & 68.5 & 11.7 \\
\hline HC-Alb3-550 & -321 & 217.2 & 6.0 & 81.0 & 13.6 \\
\hline HC-Alb3-750 & -152 & 115.2 & 5.4 & 83.3 & 15.4 \\
\hline HC-Alb3-950 & - & - & 4.5 & 88.4 & 19.7 \\
\hline HC-Alb4 & 40 & 34 & 6.1 & 66.8 & 10.9 \\
\hline HC-Alb4-350 & 36 & 36.4 & 6.3 & 68.4 & 10.9 \\
\hline HC-Alb4-550 & 106 & 106.5 & 6.4 & 79.4 & 12.4 \\
\hline HC-Alb4-750 & -1661 & 60.6 & 6.0 & 84.3 & 14.2 \\
\hline HC-Alb4-950 & 64 & 64.8 & 4.6 & 89.0 & 19.4 \\
\hline HC-Alb5 & 20 & 30 & 6.6 & 66.9 & 10.2 \\
\hline HC-Alb5-350 & 50 & 24.8 & 7.0 & 69.5 & 10.0 \\
\hline HC-Alb5-550 & 20 & 78.3 & 6.8 & 81.1 & 11.9 \\
\hline HC-Alb5-750 & 90 & 19.2 & 6.3 & 82.3 & 13.0 \\
\hline HC-Alb5-950 & - & - & 5.1 & 90.3 & 17.7 \\
\hline HC-Alb10 & 34 & 56 & 8.0 & 65.6 & 8.2 \\
\hline HC-Alb10-350 & 57 & 48.9 & 8.2 & 68.8 & 8.4 \\
\hline HC-Alb10-550 & 33 & 78.7 & 8.4 & 80.0 & 9.6 \\
\hline HC-Alb10-750 & -203 & 61.1 & 7.0 & 83.0 & 11.9 \\
\hline HC-Alb10-950 & 30 & 46.2 & 4.7 & 84.1 & 17.9 \\
\hline
\end{tabular}

The calculated BET constant values (Table 1) for low-content OvA samples are roughly twice the value of the samples obtained using a high OvA amount, suggesting that the surface properties (in terms of type and distribution of functional groups) do significantly change with increasing the OvA content. It is generally accepted that the BET constant reflects the adsorption strength of the adsorbent, and that high values generally mean higher adsorption equilibrium. The reproducibility regarding the synthesis of this material seems to be quite good, as several synthetic repeats of the sample HC-Alb2 always provided, within experimental accuracy, the same characteristics (preservation of the $\mathrm{N}_{2}$ adsorption-desorption behavior given in Figure 1 of Electronic Supplementary Information, ESI).

Surface functionalities present in the OvA-modified carbons were qualitatively examined using FT-IR and XPS (Figure S2a in ESI). The FT-IR spectra of $\mathrm{HC}$ prepared in presence of OvA show adsorption bands corresponding to carbonyl functions (peak at $\left.1699 \mathrm{~cm}^{-1-}\right)$ together with bands corresponding to $\mathrm{N}$-containing groups $\left(1580 \mathrm{~cm}^{-1}\right)$ such as amines. ${ }^{[32]}$ Resonances in the 750 $690 \mathrm{~cm}^{-1}$ region can be related to extended $\mathrm{C}=\mathrm{C}$ bonds together with C-O-C bands. $\left(1020 \mathrm{~cm}^{-1}\right) \cdot{ }^{[39]}$ However, even if ambiguity in interpretating peaks in the $1580-1600 \mathrm{~cm}^{-1}$ region exists, clear insights on carbonyl functions and $\mathrm{C}=\mathrm{C}$ groups will be shown and discussed later by mean of ${ }^{13} \mathrm{C}$ solid state NMR experiments (Figure 6) while indications of nitrogen-containing functionalities will be confirmed by N1s peaks found by XPS (ESI, Figure S2b). All in all, the resulting OvA-modified materials contain structural amino groups in addition to the typical functional groups found in hydrothermal carbons. ${ }^{[38]}$

Besides generating carbon materials with pure mesoporosity at lower temperatures and under sustainable conditions, it is of course also possible to apply temperature treatments for further strengthening of the carbonaceous scaffold. To identify optimal conditions, thermogravimetric (TGA) measurements were performed. The TGA behavior under nitrogen gas of HC-AlbX samples as compared to pure OvA and hydrothermal glucose carbon reveals a number of features (Figure S3 of ESI)). As expected, the pure protein can carbonize without residue and looses $70 \%$ of its mass already at about $400^{\circ} \mathrm{C}$, while the carbonaceous materials containing OvA show a much higher thermal resistance. At $400^{\circ} \mathrm{C}$, they loose only about $25 \%$ of their mass, while at $1000^{\circ} \mathrm{C}$ they still keep up to $40 \%$. Interestingly, hydrothermal carbons synthesized in the presence of OvA are more temperature resistant compared to pure hydrothermal carbon $(\mathrm{HC})$, showing the network strengthening effect of nitrogen on the carbon scaffold. Elemental analysis (EA) (Table 1) shows that the nitrogen content increases from 3 w\% to 8 w\% with increasing OvA content. TGA and EA therefore clearly suggest that fractions of the amino acid backbone are actually part of the carbonaceous scaffold, as otherwise one would expect an intermediary decomposition behavior between OVA and hydrothermal carbon, but not improved stability. The point of nitrogen incorporation will be discussed in more detail later.

\section{Characterization of the Carbonized Materials}

In order to obtain more insights concerning the thermal behavior and increase in carbonization by eliminating oxygen functions, 
series of samples were further condensed at different temperatures, from 350 to $950^{\circ} \mathrm{C}$ under an inert gas $\left(\mathrm{N}_{2}\right)$ atmosphere. Some of the SEM images for selected samples $\mathrm{HC}$ AlbX-Y (X=1, 2, 5; Y=350,550, $\left.750^{\circ} \mathrm{C}\right)$ can be found in the ESI (Figure S4). The microstructure of all albumine-modified materials seems to be stable against the heat treatment; in particular, no pronounced sintering or coalescence occurs (as it might be expected from tars without structural cross-linking), and the overall morphology on larger length scales appears very similar to the primary products.

TEM images in Figure 4 which can provide more insights to changes in the lower nanometer range, indeed show that the mass loss and the coupled creation of additional porosity is taken up on the scale of the carbon scaffold: Samples tempered at $350^{\circ} \mathrm{C}$ create an exciting and previously unknown "carbon foam" morphology, while further mass loss opens up transport pores between the blobs while all essential constituting elements are still kept.
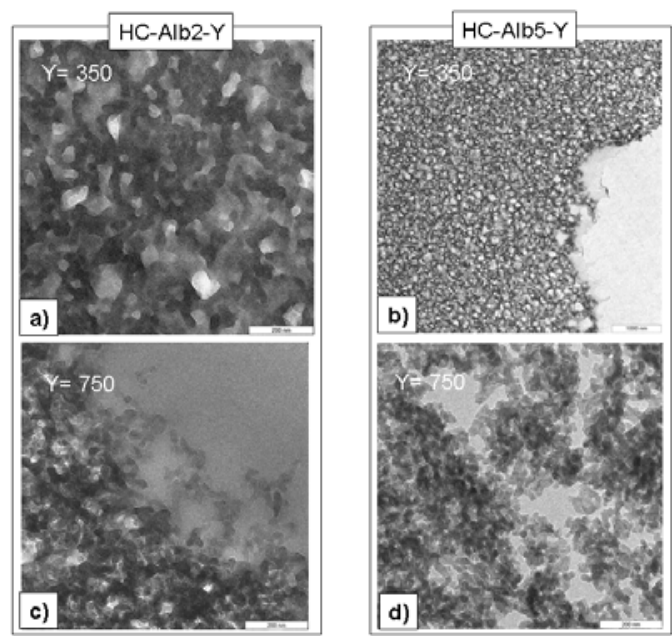

Figure 4.TEM images for higher temperature samples $\mathrm{HC}$-AlbX-Y, $\mathrm{X}=2,5$. $Y$ $(=350,750)$ indicates the calcination temperature. Scale bar is $200 \mathrm{~nm}$.

Nitrogen adsorption-desorption experiments for calcined materials were performed on all materials. An exemplary set of data is shown in Figure $5 \mathrm{a}$-b for sample HC-Alb2 treated at different calcination temperatures. The isotherms show a clear increase in gas adsorption at low relative pressures indicating an increase in surface area, while the microporosity (characterized by the apparent intercept with the $\mathrm{Y}$-axis) is staying remarkably low. The surface areas show a maximum $\left(359 \mathrm{~m}^{2} / \mathrm{g}\right)$ for the samples calcined at around $550^{\circ} \mathrm{C}$, while values for samples treated at higher temperatures are lower. We attribute this feature to the onset of tectonic carbon rearrangements (promoted by nitrogen moieties) which lower the exposed surface of the scaffold structure. This behavior is seen for practical all the compositions, as quantified in Table 1.
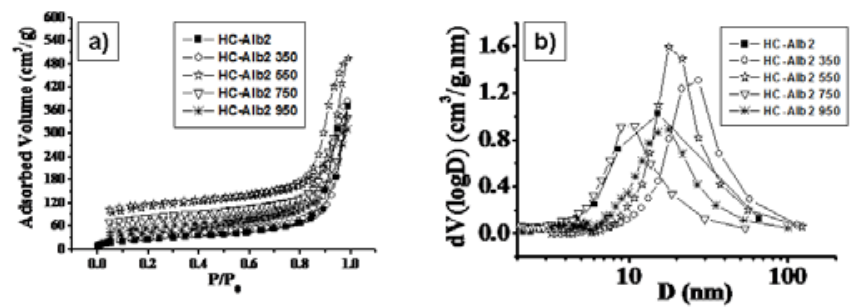

Figure 5. Nitrogen adsorption-desorption isotherms for samples HC-Alb2-Y ( $\mathrm{Y}=$ $350,550,750,950)$; b) BJH pore size distribution curves for samples HC-Alb2$\mathrm{Y}$

In good agreement with the TGA behavior and in spite of the "ripening" of the carbon foam structure seen in TEM, treatment at $350^{\circ} \mathrm{C}$ does not affect the adsorption properties and the overall $\mathrm{C} / \mathrm{N}$ ratio too much: all $\mathrm{N}_{2}$ adsorption-desorption isotherms appear very similar and are generally within a $10 \%$ variation, exception made for the sample with very low OvA content, HCAlb1 and HC-Alb1-350, where variation reaches 25\% (Table 1).

FT-IR experiments (Figure 5, ESI) indicate that treatment at $350^{\circ} \mathrm{C}$ results in a partial loss of carbonyl groups, as indicated by the decrease of the correspondent peak bound to unsaturated carbons at $1650 \mathrm{~cm}^{-1} \cdot{ }^{[62-64]}$ Carbonyl functions bound to saturated carbons (peak at $1699 \mathrm{~cm}^{-1}$ ) disappear only after treatment at $550^{\circ} \mathrm{C}$ (Figure $5, \mathrm{ESI}$ ) while $\mathrm{N}$-containing groups $\left(1580 \mathrm{~cm}^{-1}\right)^{[32]}$ are present up to the highest temperature.

Structural changes with temperature were also investigated using ${ }^{13} \mathrm{C}$ CP-MAS solid state NMR (Figure 6). Using solid state ${ }^{13} \mathrm{C} \mathrm{CP}$ MAS NMR, the local structure of hydrothermal carbons obtained from glucose was recently revealed, ${ }^{[35]}$ and it was found out that hydroxymethylfurfural (the main decomposition product of glucose) is the main monomer of carbon formation, involving polymerization towards polyfuranes and formation of a conjugated system, while still maintaining a high number of oxygenated functionalities bound to the furan rings. When $\mathrm{HC}$ is prepared in presence of OvA, its corresponding ${ }^{13} \mathrm{C}$ spectrum (HC-Alb2 in Figure 6) shows very similar features in the carbonyl and aliphatic regions as observed for pure $\mathrm{HC}$ from glucose, but, interestingly, the amount of delocalized aromatic $\mathrm{sp}^{2}$-carbons is much higher (peak at $130 \mathrm{ppm}$ ), while the amount of furane moieties is significantly decreased (150 and $110 \mathrm{ppm})$. This clearly suggests that the existence of reactive nitrogen promotes the formation of a graphitic like structure where $\mathrm{N}$ is presumably incorporated in form of $\mathrm{C}=\mathrm{C}-\mathrm{N}$ bonds. This information is strongly supported by XPS analysis shown discussed below. Upon further heat treatment at $550^{\circ} \mathrm{C}$, the peak at $130 \mathrm{ppm}$ dominates the spectrum, which is typical for graphitic structures. This clearly indicates that nanoparticles with an aromatic core are formed, while most oxygenated functions have been removed.

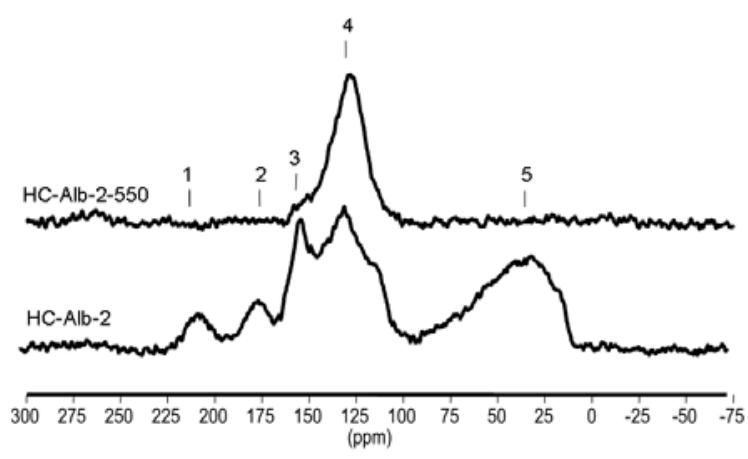

Figure $6 .{ }^{13} \mathrm{C}$ CPMAS solid state NMR for the HC-Alb-2 before and after heat treatment at $\mathrm{T}=550^{\circ} \mathrm{C}$. Peak attribution: 1 - ketones and aldehydes; 2 - 
carboxylic acids and/or esters; 3 - (oxygen-bound C=C groups); 4 - delocalized $\mathrm{C}=\mathrm{C}$ groups; 5 - aliphatic groups.

Besides the structural control of the carbons towards a nanosponge architecture, thermally stable functionalization of the carbonaceous scaffold with nitrogen using OvA as a nitrogen source was a second task being successfully accomplished. Elemental analysis (Table 1) shows that the carbon content increases with temperature from about $67 \%$ for bare hydrothermal carbons to $84 \%$ while the nitrogen content stays almost constant at relatively high values up to $\mathrm{T}=750^{\circ} \mathrm{C}$, while the $\mathrm{T}=950^{\circ} \mathrm{C}$ data show only a slight decline. This is a proof that the nitrogen is included within the carbon scaffold in the form of (highly beneficial) aromatic nitrogen units thus contributing to both the electronic and chemical behavior of the material. XPS analysis (ESI, Figure 2 b, c) confirms such an interpretation. The HC-Alb2 material shows the co-existence of amines, pyrrolic and quaternary nitrogen groups while, after treatment at $550^{\circ} \mathrm{C}$, a large component at $398.7 \mathrm{eV}$ appears while a shift from 400.1 to $400.7 \mathrm{eV}^{[65]}$ occurs. These data clearly indicate the existence of aromatic amine groups like pyridine, which is in complete accordance with the ${ }^{13} \mathrm{C}$ solid state NMR data indicating the dominance of aromatic graphitic structures.

Zeta-potential experiments as a function of $\mathrm{pH}$ on the HC-Alb2-Y sample series (Figure 7) can further characterize the nitrogen functions. The as-synthesized hydrothermal powders (Figure 7a) clearly show positive zeta-potentials below $\mathrm{pH} \sim 4$ indicating the coexistence of positively charged amino groups at the particle's surface with more negatively charged oxygen moieties. In addition, the quantitative zeta-potential values at $\mathrm{pH}=2.3$ increase with increasing content of nitrogen within the materials, the highest value $(+26.6 \mathrm{mV})$ belonging to $\mathrm{HC}-\mathrm{Alb} 10(8 \% \mathrm{~N})$ and the lowest $(+9.7 \mathrm{mV})$ belonging to HC-Alb1 $(3 \% \mathrm{~N})$. Pure hydrothermal carbon from glucose shows no positive zetapotential value in the whole examined range, as expected. Analyzing the effects of calcination on the zeta-potential (Figure 7 b) it is found that the positive character at low $\mathrm{pH}$ is not affected by temperature treatment. The material is overall even more basic, as the isoelectric point shifts towards higher $\mathrm{pH}$ values. This can be connected with the FT-IR and ${ }^{13} \mathrm{C}$ solid state NMR observations which show that the oxidic surface functions $(\mathrm{COOH}$ $\mathrm{OH}$ ) are degraded with temperature. The absolute zeta-potential value in the low $\mathrm{pH}$ range does not increase with temperature but stays constant at $+18 \mathrm{mV}$. Again, we attribute that to the conversion of primary and secondary amine groups to aromatic nitrogen moieties generated and being stable at higher temperatures.
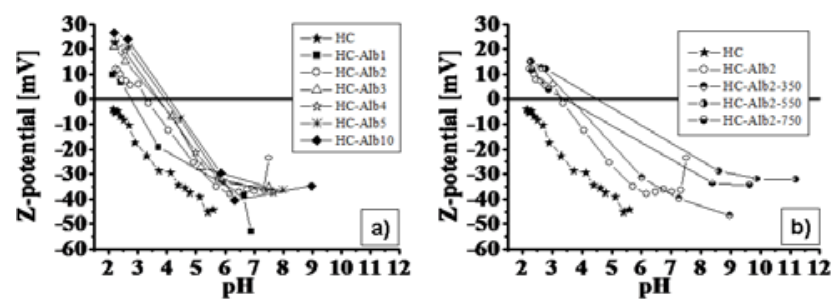

Figure 7. Zeta-potential experiments on a) $\mathrm{HC}$-AlbX (X=1, 2, 3, 4, 5, 10) and b) HC-Alb2-Y $(Y=350,550,750)$ materials. $\mathrm{HC}$ indicates the hydrothermal carbon synthesized without OvA as reference.
These results show that OvA takes an active role in the carbonformation reactions: 1) it stabilizes the precipitating carbon in the hydrothermal reaction as nanosized particles; 2) by crossreactions with the condensing monomers it brings up to $8 \mathrm{w} \%$ nitrogen to the final carbonaceous material. It is known from previous studies ${ }^{[66-69]}$ that glucose dehydrates three times to form hydroxymethyl furfural (HMF) in a first step, which is the main intermediate reacting species to form the carbonaceous scaffold. ${ }^{[35,38]}$ In presence of proteins and amino acids, the aldehydic group of HMF will react to form Schiff bases and then to Maillard products, as it was previously documented in the chemistry of $\mathrm{HMF}^{[70]}$ and furans in general..$^{[71]}$ with amino-group containing molecules such as amino acids. ${ }^{[72]}$

Similar experiments using other common proteins (hemoglobin, gelatin, casein; results not shown) revealed a systematic increase in nitrogen content of the carbon as a function of protein but within this series a sensible reduction of the primary particle size was not found. We have observed during preliminary experiments that use of molecules with accentuated hydrophobic character or amphiphilic molecules act as emulsion stabilizers. As reported in the experimental part, half of the OvA amino acid residues are hydrophobic, and it displays surface activity. Under the reaction conditions, the protein certainly reacts via the Maillard reaction with the polysaccharide, obviously creating an effective stabilizer for the intermediate droplets later transferring to carbon.

\section{Conclusion}

We have demonstrated that it is possible to synthesize well defined carbonaceous nanostructures with a developed spongelike mesopore system by using hydrothermal treatment at $180^{\circ} \mathrm{C}$ of glucose in the presence of ovalbumin. This simple process provides a unique and sustainable pathway to control the primary particle stability in hydrothermal carbonization, resulting in the formation of nanometer-sized sponge scaffolds composed of spherical particles $(20-50 \mathrm{~nm})$. Another advantage beside the morphological control is that the protein efficiently introduces nitrogen functions (as much as $8 \mathrm{wt} \%$ ) into the carbonaceous scaffold, which are known to be very favourable for catalysis, adsorption, energy storage devices, and also to increase the oxidation stability of engineering carbons. Classical characterization methods (nitrogen adsorption-desorption, TEM, SEM, FTIR, XPS and elemental analysis) were used to describe the porous carbon structures. Temperature treatments have shown that all materials keep the nitrogen content almost unchanged up to $950^{\circ} \mathrm{C}$, while providing a higher thermal and oxidation stability as compared to pure carbon based hydrothermal scaffolds. This was attributed to a remarkably increased aromaticity.

Last but not least, the whole synthetic process occurs in an energy and atom-saving fashion from cheap and sustainable resources, as employed temperatures in the first step remain below $200^{\circ} \mathrm{C}$ and neither metals nor surfactants have been used to catalyze and control the reaction. Even if this work has employed pure model compounds, we believe that more complex biomass like starch or chicken egg white might be actually employed in a similar fashion, resulting potentially even in a wide variety of structures. 


\section{Experimental Section}

Synthesis. For all samples, $13.5 \mathrm{ml}$ of a deionized water solution containing $1.5 \mathrm{~g}$ of $\mathrm{D}(+)$-glucose and variable amount of ovalbumin (OvA) was used. $\mathrm{D}(+)$-glucose (CAS: 50-99-7) and ovalbumin (OvA) from chicken egg white (grade $V$, CAS: 9006-59-1) were used as received (Sigma Aldrich). OvA is the major component of egg white (54\%) and is a phosphoglycoprotein with a molecular mass of about $45 \mathrm{kDa}^{[73]}$ and a sequence of 385 amino acids ${ }^{[74]}$ including one disulfidic bond, four sulfhydryl groups, zero to two phosphoryl groups and a carbohydrate chain. ${ }^{[75]}$ Half of OvA amino acids residues are hydrophobic and one third are charged, for the most part acidic, giving to the molecule an isoelectric point (IEP) of 4.5. ${ }^{[76]}$

The mixture was sealed into a glass vial inside a typical PTFE-lined autoclave system and hydrothermally reacted at $180^{\circ} \mathrm{C}$ for $24 \mathrm{~h}$. After reaction, the autoclave is cooled down in a water bath at room temperature. The obtained black solid flake-like powder is then separated from the remaining aqueous solution by filtration and put into an oven at $80^{\circ} \mathrm{C}$ under vacuum overnight for drying. Further calcination was performed under a $\mathrm{N}_{2}$ flow using a $1^{\circ} \mathrm{C} / \mathrm{min}$ ramp from room up to the desired temperature, at which the sample is left for $4 \mathrm{~h}$. Typical sample notation follows: HC-AlbX, where $X$ stands for the amount of OvA introduced $(X=1,2,3,4,5,10$, respectively for $0.15 \mathrm{~g}, 0.30 \mathrm{~g}, 0.45 \mathrm{~g}, 0.50 \mathrm{~g}, 0.75 \mathrm{~g}$ and $1.50 \mathrm{~g}$ ). Calcined samples are referred to $\mathrm{HC}$-AlbX-Y, where $\mathrm{Y}$ stands for the calcination temperature $(Y=350,550,750$ and 950$)$ given in degrees celtius.

\section{Characterization.}

(a) Elemental analysis. Chemical analysis was performed on a (C, N $\mathrm{O}, \mathrm{S}, \mathrm{H}$ ) Elementar Vario Micro Cube.

(b) Scanning Electron Microscopy. SEM images were acquired on a LEO 1550/LEO GmbH Oberkochen provided with a Everhard Thornley secondary electron and In-lens detectors.

(c) Transmission Electron Microscopy. TEM was perfermed on a Zeiss EM 912 instrument equipped with CCD camera and a filament of $\mathrm{LaB}_{6}$ under a $120 \mathrm{kV}$ tension. All samples are microtomed.

(d) Porosimetry. $\mathrm{N}_{2}$ adsorption and desorption isotherms were performed at $77 \mathrm{~K}$ with a Quadrachrome Adsorption Instrument; BET and $\mathrm{BJH}$ methods was used for specific surface area determination and pore size distribution calculations.

(e) Thermogravimetric analysis. TGA was performed on a Netzsch Iris TG $209 \mathrm{FI}$ instrument under nitrogen gas from room temperature to $1000^{\circ} \mathrm{C}$ using a $5^{\circ} \mathrm{C} / \mathrm{min}$ ramp.

(f) Infrared spectroscopy. FT-IR spectroscopy was done in ATR geometry on a Varian 1000 FT-IR spectrometer, Scimitar Series (FTS 1000) between $4000-600 \mathrm{~cm}^{-1}$.

(g) Surface charge analysis. Z-potential measurements were realized on a Malvern Zetasizer Nano ZS instrument. Carbon powders were dispersed and stirred $(400 \mathrm{rpm})$ in water $\left(\mathrm{C}_{\mathrm{NaCl}}=0.03 \mathrm{M}\right)$ at different $\mathrm{pH}$ values for three days at $25^{\circ} \mathrm{C}$ to reach equilibrium. Disposable clear zeta cells (DTS1060c) were used for determing the zeta potential, which was calculated by Smoluchowski's equation via the measurement of the electrophoretic mobility. ${ }^{[77]}$ Due to the heterogenous nature of our samples, in order to avoid immediate pollution of the electrodes, all solutions were filtered using PTFE $5 \mu \mathrm{m}$ disposable filters and fast monomodal acquisition setting (suitable for high conductivity solution and no distribution plot is required, voltage is set automatically according to the conductivity of the sample) was used. Although the zeta potentials of the anisotropic particles obtained by Smoluchowski's equation may be underestimated, ${ }^{[78]}$ they are still useful to qualitatively understand the effects of the surface charge of the $\mathrm{HC}$ particles.

(h) Solid state NMR. ${ }^{1} \mathrm{H}$ and ${ }^{13} \mathrm{C}$ solid-state Magic Angle Spinning (MAS) NMR experiments have been acquired on Bruker Avance 300 $\mathrm{MHz}(7 \mathrm{~T})$ spectrometer using the $4 \mathrm{~mm}$ zirconia rotors as sample holders spinning at MAS rate $v_{\text {MAS }}=14 \mathrm{kHz}$. The chemical shift reference was tetramethylsilane (TMS; $\delta=0 \mathrm{ppm}$ ). Proton-to-carbon CP MAS was used to enhance carbon sensitivity: recycle delays for HC-Alb2 and HC-Alb2-550 samples are, respectively, 3 and $5 \mathrm{~s}$ and TPPM decoupling is applied during signal acquisition. Crosspolarization transfers were performed under adiabatic tangential ramps ${ }^{[79,80]}$ to enhance the signal with respect to other known methods $^{[81]}$ and $\mathrm{CP}$ time $\mathrm{t}_{\mathrm{CP}}=3 \mathrm{~ms}$ was found to be a good compromise in order to have a good overview on all carbon species. Number of transients is 1200 . Peak attribution was done after references ${ }^{[82-86]}$ and after supporting information.

(i) X-ray Photoelectron spectroscopy. XPS spectra were collected at the facilities of the Laboratoire de Réactivité de Surface (University Pierre et Marie Curie, Paris, France) on a SPECS (Phoibos MCD 150) X-ray photoelectron spectrometer, using a Mg Ka X-ray source ( $\mathrm{hv}=1253.6 \mathrm{eV})$ having a $150 \mathrm{~W}(12 \mathrm{~mA}, 12.5 \mathrm{kV})$ electron beam power and a $7 \times 2 \mathrm{~mm}$ spot size. The emission of photoelectrons from the sample was analyzed under ultrahigh vacuum conditions (10-8 $\mathrm{Pa})$. High-resolution spectra were collected at pass energy of $10 \mathrm{eV}$ for $\mathrm{C} 1 \mathrm{~s}, \mathrm{O} 1 \mathrm{~s}$, and N1s core XPS levels. After collection, the binding energies were calibrated with respect to either the $\mathrm{C}-\mathrm{C} / \mathrm{C}-\mathrm{H}$ components of the $\mathrm{C} 1 \mathrm{~s}$ peak at a binding energy of $284.8 \mathrm{eV}$. The spectral decomposition was performed by using Gaussian functions after background subtraction.

\section{Acknowledgements}

Dr. Lorenzo Stievano and Christophe Méthivier (Laboratoire de Réactivité de Surface, University Pierre et Marie Curie, Paris, France) are gratefully acknowledged for the XPS mesurements.

Keywords: ((carbon nanoparticles · hydrothermal carbonization · green chemistry $\cdot$ nanostructured carbon ))

[1] E. H. L. Falcao, F. Wudl J. Chem. Technol. Biotechnol. 2007, 82, 524531.

[2] D. Tasis, N. Tagmatarchis, A. Bianco, M. Prato Chem. Rev. 2006, 106, 1105-1136.

[3] O. A. Shenderova, V. V. Zhirnov, D. W. Brenner Crit. Rev. Solid State Mat. Sci. 2002, 27, 227-356.

[4] P. M. Ajayan Chem. Rev. 1999, 99, 1787-1799.

[5] R. Ryoo, S. H. Joo, S. Jun J. Phys. Chem. B. 1999, 103, 7743-7746.

[6] Y. Meng, D. Gu, F. Q. Zhang, Y. F. Shi, H. F. Yang, Z. Li, C. Z. Yu, B. Tu, D. Y. Zhao Angew. Chem.-Int. Edit. 2005, 44, 7053-7059.

[7] F. Q. Zhang, Y. Meng, D. Gu, Y. Yan, C. Z. Yu, B. Tu, D. Y. Zhao J. Am. Chem. Soc. 2005, 127, 13508-13509.

[8] B. Sakintuna, Y. Yurum Ind. Eng. Chem. Res. 2005, 44, 2893-2902.

[9] J. Yu, Q. Zhang, J. Ahn, S. F. Yoon, Rusli, Y. J. Li, B. Gan, K. Chew J. Mater. Sci. Lett. 2002, 21, 543-545

[10] P. M. Ajayan, J. M. Nugent, R. W. Siegel, B. Wei, P. Kohler-Redlich Nature. 2000, 404, 243-243.

[11] D. Kim, Y. Hwang, S. I. Cheong, J. K. Lee, D. Hong, S. Moon, J. E. Lee, S. H. Kim J. Nanopart. Res. 2008, 10, 1121-1128.

[12] H. P. Liu, T. Ye, C. D. Mao Angew. Chem.-Int. Edit. 2007, 46, 6473-6475. 
[13] B. Mohanty, A. K. Verma, P. Claesson, H. B. Bohidar Nanotechnology 2007, 18

[14] M. S. Mauter, M. Elimelech Environ. Sci. Technol. 2008, 42, 5843-5859.

[15] Y. F. Jia, C. J. Steele, I. P. Hayward, K. M. Thomas Carbon. 1998, 36, 1299-1308.

[16] C. P. Huang, M. H. Wu Water Res. 1977, 11, 673-679.

[17] A. H. Yan, B. W. Lau, B. S. Weissman, I. Kulaots, N. Y. C. Yang, A. B Kane, R. H. Hurt Adv. Mater. 2006, 18, 2373-+.

[18] N. W. S. Kam, T. C. Jessop, P. A. Wender, H. J. Dai J. Am. Chem. Soc. 2004, 126, 6850-6851.

[19] D. Pantarotto, J. P. Briand, M. Prato, A. Bianco Chem. Commun. 2004 16-17.

[20] A. C. Dillon, K. M. Jones, T. A. Bekkedahl, C. H. Kiang, D. S. Bethune, M. J. Heben Nature. 1997, 386, 377-379.

[21] A. A. Zakhidov, R. H. Baughman, Z. Iqbal, C. X. Cui, I. Khayrullin, S. O. Dantas, I. Marti, V. G. Ralchenko Science. 1998, 282, 897-901.

[22] P. K. Vemula, G. John Accounts Chem. Res. 2008, 41, 769-782.

[23] C. J. Murphy J. Mater. Chem. 2008, 18, 2173-2176.

[24] J. A. Dahl, B. L. S. Maddux, J. E. Hutchison Chem. Rev. 2007, 107, 2228-2269.

[25] D. Hulicova, M. Kodama, H. Hatori Chem. Mat. 2006, 18, 2318-2326.

[26] G. Lota, B. Grzyb, H. Machnikowska, J. Machnikowski, E. Frackowiak Chem. Phys. Lett. 2005, 404, 53-58.

[27] Y. P. Sun, K. F. Fu, Y. Lin, W. J. Huang Accounts Chem. Res. 2002, 35, 1096-1104.

[28] K. Jurewicz, K. Babel, A. Ziolkowski, H. Wachowska, M. Kozlowski in Ammoxidation of brown coals for supercapacitors, Vol. (Ed.^ Eds.: Editor), City, 2002, pp.191-198.

[29] C. T. Hsieh, H. Teng Carbon. 2002, 40, 667-674.

[30] Y. Y. Shao, J. H. Sui, G. P. Yin, Y. Z. Gao Appl. Catal. B-Environ. 2008 79, 89-99.

[31] M. G. Plaza, C. Pevida, A. Arenillas, F. Rubiera, J. J. Pis in $\mathrm{CO}_{2}$ capture by adsorption with nitrogen enriched carbons, Vol. (Ed. ${ }^{\wedge}$ Eds.: Editor), City, 2006, pp.2204-2212.

[32] Y. F. Jia, B. Xiao, K. M. Thomas Langmuir. 2002, 18, 470-478.

[33] Q. Wang, H. Li, L. Q. Chen, X. J. Huang in Novel spherical microporous carbon as anode material for Li-ion batteries, Vol. (Ed.^Eds.: Editor), City, 2001, pp.43-50.

[34] Q. Wang, H. Li, L. Q. Chen, X. J. Huang Carbon. 2001, 39, 2211-2214.

[35] M. M. Titirici, M. Antonietti, N. Baccile Green Chem. 2008, 10, 1204-1212.

[36] M. M. Titirici, A. Thomas, S. H. Yu, J. O. Muller, M. Antonietti Chem. Mat. 2007, 19, 4205-4212.

[37] M. M. Titirici, A. Thomas, M. Antonietti New J. Chem. 2007, 31, 787-789.

[38] M. M. Titirici, A. Thomas, M. Antonietti Adv. Funct. Mater. 2007, 17, 1010-1018.

[39] V. Budarin, J. H. Clark, J. J. E. Hardy, R. Luque, K. Milkowski, S. J. Tavener, A. J. Wilson Angew. Chem. -Int. Edit. 2006, 45, 3782-3786.

[40] R. J. White, V. L. Budarin, J. H. Clark ChemSusChem. 2008, 1, 408-411.

[41] C. Yao, Y. Shin, L. Q. Wang, C. F. Windisch, W. D. Samuels, B. W. Arey, C. Wang, W. M. Risen, G. J. Exarhos J. Phys. Chem. C. 2007, 111, 15141-15145.

[42] V. L. Budarin, J. H. Clark, R. Luque, D. J. Macquarrie, A. Koutinas, C. Webb Green Chem. 2007, 9, 992-995.

[43] V. Budarin, R. Luque, D. J. Macquarrie, J. H. Clark Chem.-Eur. J. 2007, 13, 6914-6919.

[44] S. H. Yu, X. J. Cui, L. L. Li, K. Li, B. Yu, M. Antonietti, H. Colfen Adv. Mater. 2004, 16, 1636-+

[45] M. M. Tusi, M. Brandalise, O. V. Correa, A. Oliveira Neto, M. Linardi, E. V. Spinacé. 2007, 10, 171-175

[46] M. Sevilla, G. Lota, A. B. Fuertes J. Power Sources. 2007, 171, 546-551.

[47] H. S. Qian, G. F. Lin, Y. X. Zhang, P. Gunawan, R. Xu Nanotechnology. 2007, 18

[48] X. J. Cui, M. Antonietti, S. H. Yu Small. 2006, 2, 756-759.

[49] X. M. Sun, J. F. Liu, Y. D. Li Chem.-Eur. J. 2006, 12, 2039-2047

[50] X. M. Sun, Y. D. Li Angew. Chem.-Int. Edit. 2004, 43, 597-601.

[51] H. X. Yang, J. F. Qian, Z. X. Chen, X. P. Ai, Y. L. Cao J. Phys. Chem. C. 2007, 111, 14067-14071.
[52] K. Zhu, K. Egeblad, C. H. Christensen Eur. J. Inorg. Chem. 2007, 39553960

[53] J. Hu, H. Li, X. J. Huang Solid State Ion. 2007, 178, 265-271.

[54] M.-M. Titirici, M. Antonietti, A. Thomas Chem. Mat. 2006, 18, 3808-3812.

[55] X. Sun, Y. Li Angewandte Chemie 2004, 116, 3915-3919.

[56] E. Berl, A. Schmidt Justus Liebigs Annalen Der Chemie. 1932, 493, $97-$ 123.

[57] H. Qian, M. Antonietti, S.-H. Yu Adv. Funct. Mater. 2007, 17, 637-643.

[58] H. S. Qian, S. H. Yu, L. B. Luo, J. Y. Gong, L. F. Fei, X. M. Liu Chem. Mat. 2006, 18, 2102-2108.

[59] M. M. Titirici, A. Thomas, M. Antonietti J. Mater. Chem. 2007, 17, 3412 3418.

[60] V. L. Budarin, J. H. Clark, R. Luque, D. J. Macquarrie Chem. Commun. 2007, 634-636.

[61] P. Kumar, S. Karmakar, H. B. Bohidar J. Phys. Chem. C. 2008, 112 15113-15121.

[62] R. Sanchez, C. Hernandez, G. Keresztury Eur. Polym. J. 1994, 30, 43-50.

[63] C. Mealares, Z. Hui, A. Gandini Polymer. 1996, 37, 2273-2279.

[64] A. Shindo, K. Izumino Carbon. 1994, 32, 1233-1243.

[65] J. R. Pels, F. Kapteijn, J. A. Moulijn, Q. Zhu, K. M. Thomas Carbon. 1995 33, 1641-1653.

[66] H. E. van Dam, A. P. G. Kieboom, H. Vanbekkum Starch-Starke. 1986, 38, 95-101.

[67] W. N. Haworth, W. G. M. Jones Journal of the Chemical Society. 1944 667-670.

[68] B. F. M. Kuster Starch-Starke. 1990, 42, 314-321.

[69] M. J. Antal, W. S. L. Mok, G. N. Richards Carbohydr. Res. 1990, 199, 91-109.

[70] J. Lewkowski Arkivoc. 2001, 2.

[71] A. Gandini, M. N. Belgacem Prog. Polym. Sci. 1997, 22, 1203-1379.

[72] T. Hofmann J. Agric. Food Chem. 1998, 46, 932-940.

[73] R. C. Warner in, Vol. 2 Part A (Eds.: H. Neurath, K. Bailey), Academic Press, New York, 1954, pp.p. 443.

[74] L. McReynolds, B. W. Omalley, A. D. Nisbet, J. E. Fothergill, D. Givol, S. Fields, M. Robertson, G. G. Brownlee Nature. 1978, 273, 723-728.

[75] A. D. Nisbet, R. H. Saundry, A. J. G. Moir, L. A. Fothergill, J. E. Fothergill Eur. J. Biochem. 1981, 115, 335-345

[76] E. Li-Chan, S. Nakai Critical Reviews in Poultry Biology. 1989, 2, 21-58.

[77] R. J. Hunter, Zeta potential in colloid science : principles and applications, Acad. Pr., London, 1981.

[78] R. R. Johnson, A. T. C. Johnson, M. L. Klein Nano Lett. 2008, 8, 69-75.

[79] S. Hediger, B. H. Meier, N. D. Kurur, G. Bodenhausen, R. R. Ernst Chem. Phys. Lett. 1994, 223, 283-288.

[80] S. Hediger, B. H. Meier, R. R. Ernst Chem. Phys. Lett. 1995, 240, 449456.

[81] S. C. Christiansen, N. Hedin, J. D. Epping, M. T. Janicke, Y. del Amo, M. Demarest, M. Brzezinski, B. F. Chmelka Solid State Nucl. Magn. Reson. 2006, 29, 170-182.

[82] K. M. Holtman, H. M. Chang, H. Jameel, J. F. Kadla J. Wood Chem. Technol. 2006, 26, 21-34.

[83] R. K. Sharma, J. B. Wooten, V. L. Baliga, P. A. Martoglio-Smith, M. R. Hajaligol J. Agric. Food Chem. 2002, 50, 771-783.

[84] M. J. Sullivan, G. E. Maciel Anal. Chem. 1982, 54, 1606-1615.

[85] P. F. Barron, M. A. Wilson Nature. 1981, 289, 275-276.

[86] E. Breitmaier, W. Voelter, Carbon- ${ }^{13} \mathrm{NMR}$ spectroscopy : high-resolution methods and applications in organic chemistry and biochemistry, $\mathrm{VCH}$, Weinheim, 1990

Received: ((will be filled in by the editorial staff))

Published online: ((will be filled in by the editorial staff)) 


\section{Supporting Information}

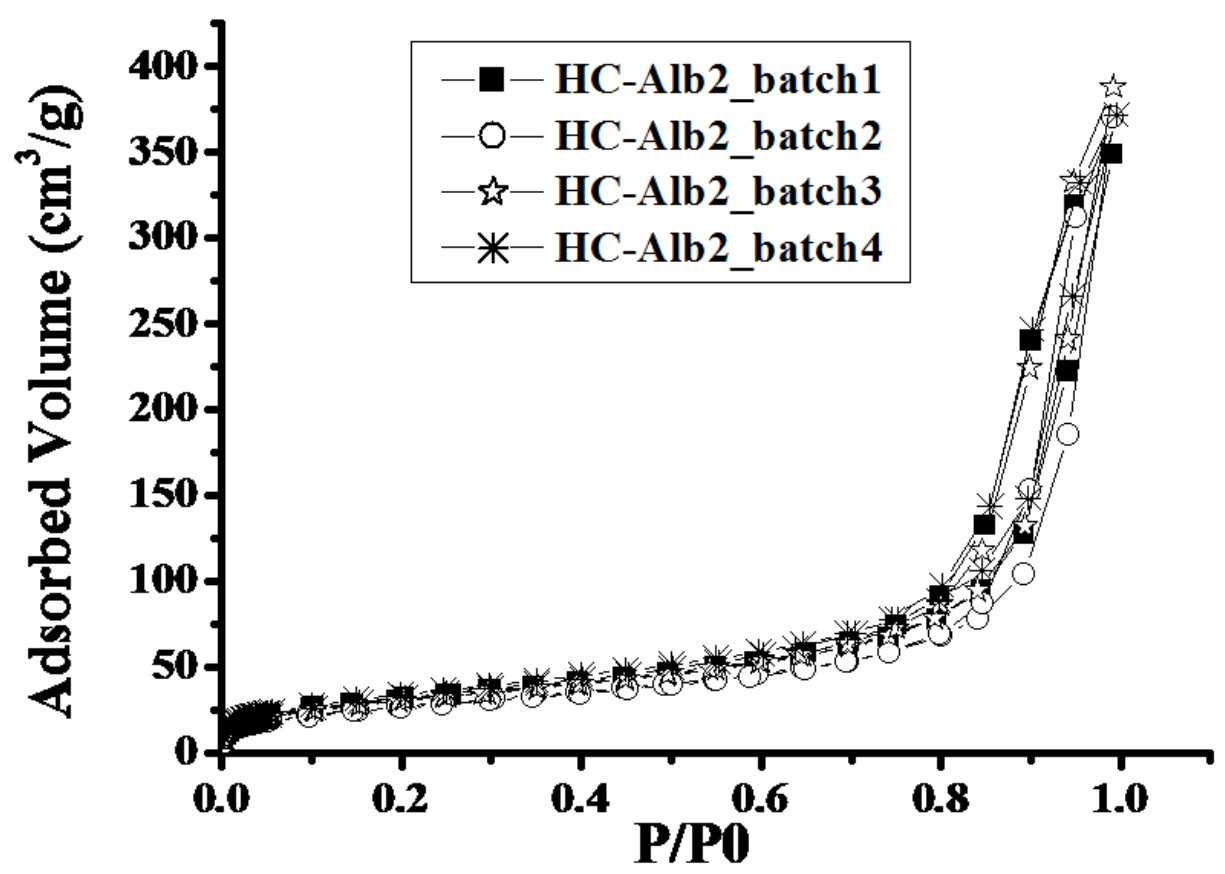

(ESI) Figure 1 - Nitrogen adsorption-desorption isotherms for different synthesis batches for sample HC-Alb2 

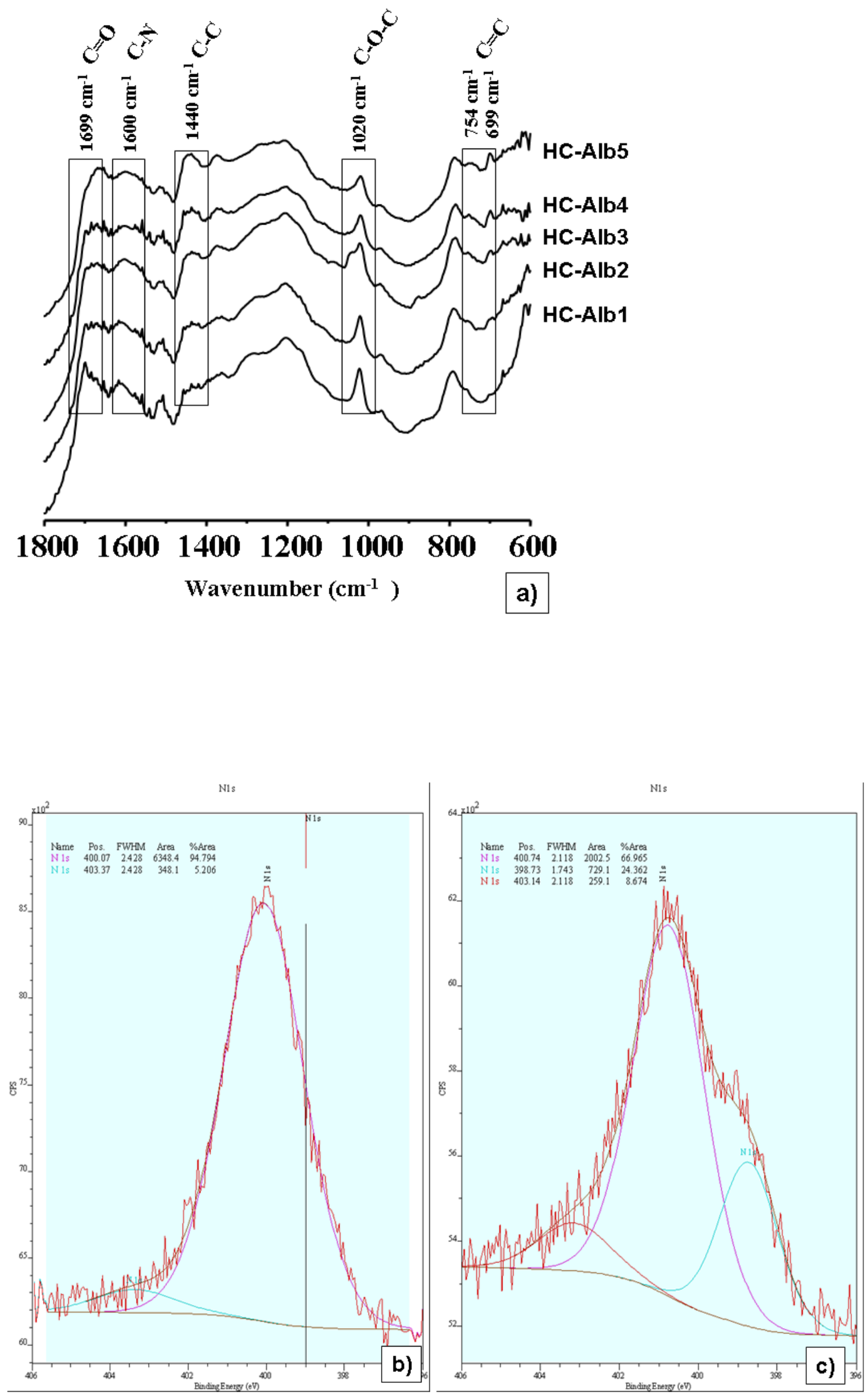

(ESI) Figure 2 - a) FT-IR spectra for as-synthesized HC-AlbX (X=1-5) samples; N1s XPS 
spectra for b) HC-Alb2 and c) HC-Alb2-550 samples

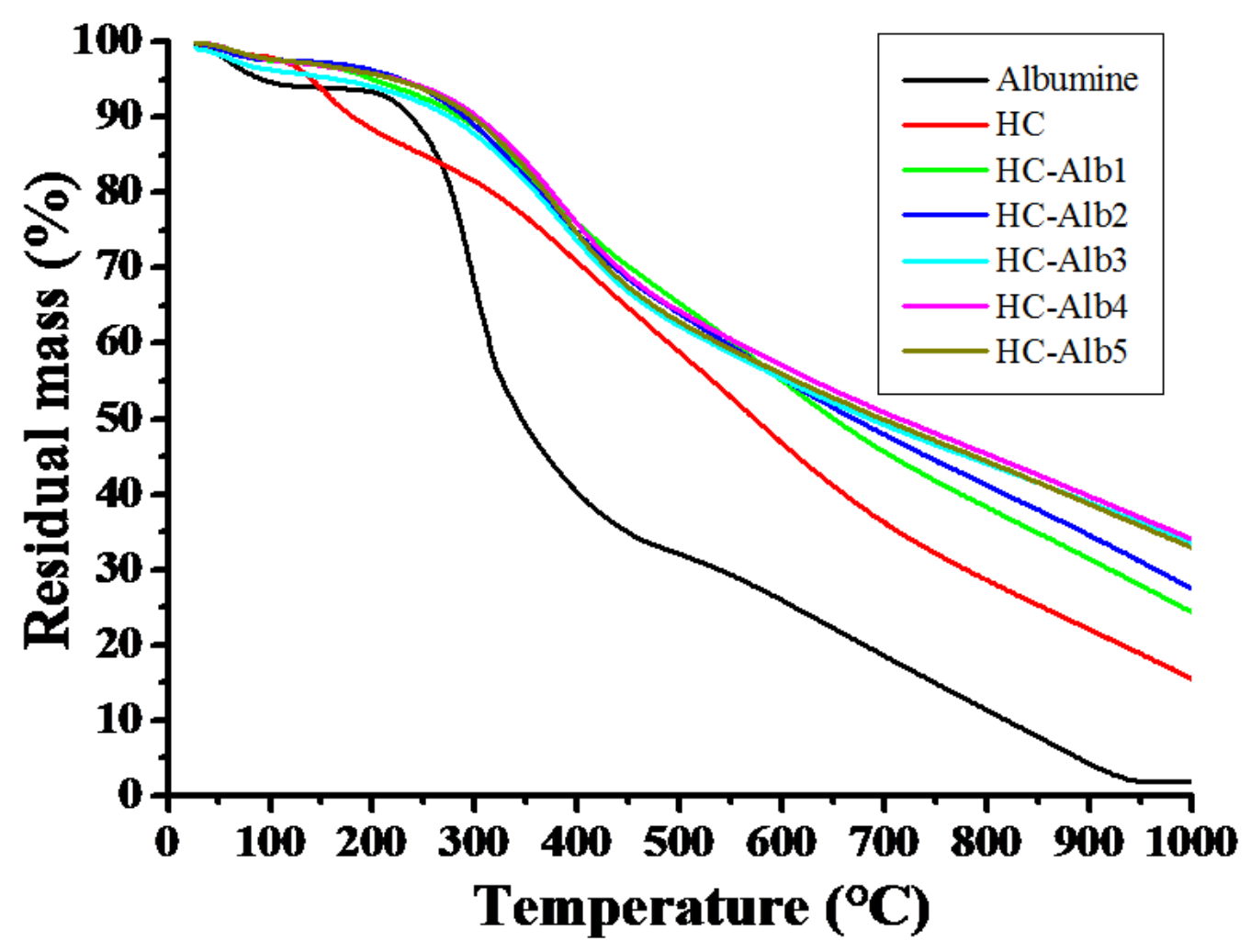

(ESI)Fig 3 - TGA analysis of pure OvA, HC from pure glucose and HC-AlbX materials

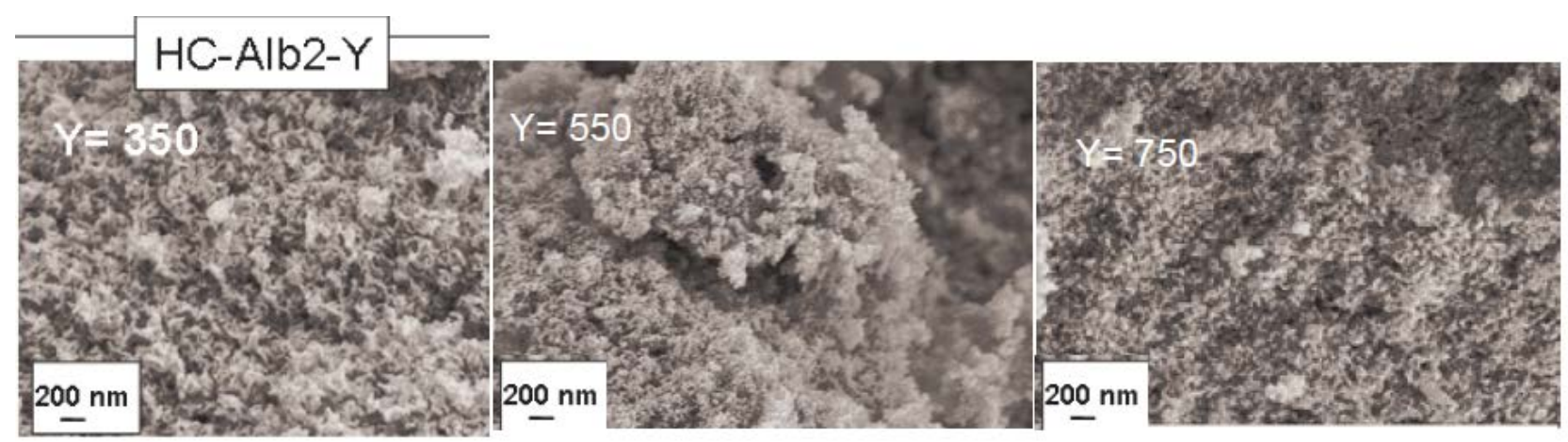

(ESI) Figure 4 - (ESI) Figure 4 - SEM images for further carbonized samples HC-Alb2-Y (Y=350, $550,750)$. Scale bar is $200 \mathrm{~nm}$. 


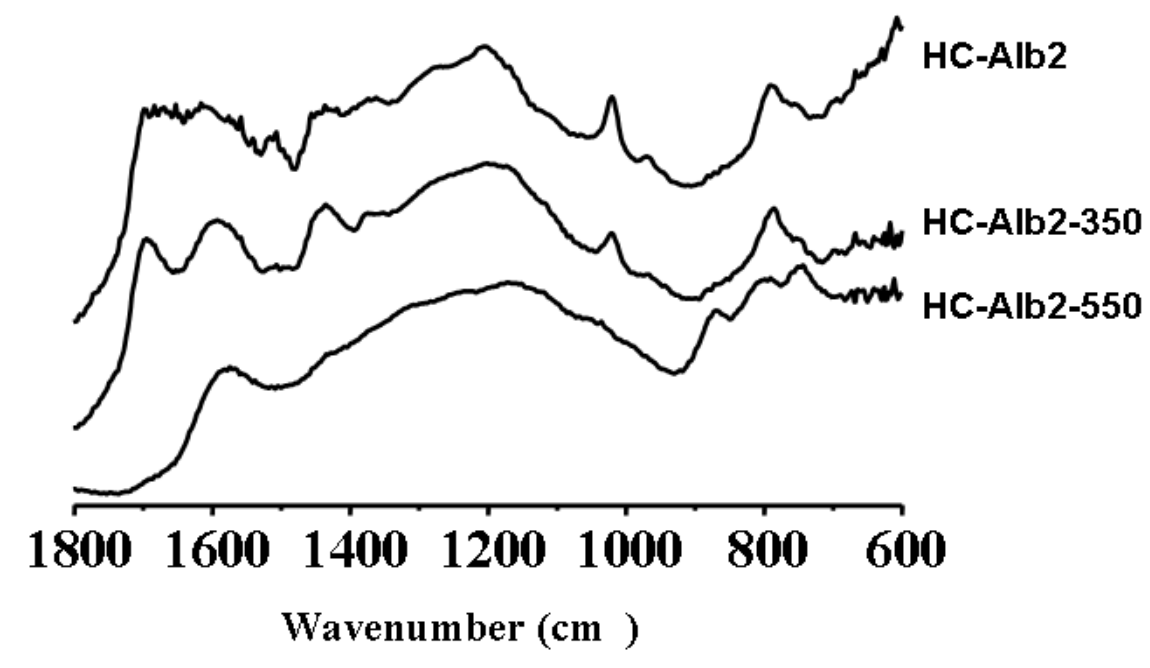

(ESI) Figure 5 - FT-IR spectra for as-synthesized and calcined HC-Alb2 samples 
Entry for the Table of Contents (Please choose one layout)

\section{Layout 1:}

\section{FULL PAPER}

In this work, we present a simple and green one-step pathway towards nitrogen-doped carbon nanostructures with controlled mesoporosity via hydrothermal treatment of glucose in the presence of model proteins. Chicken egg white
Ovalbumin (OvA) Ovalbumin (O)A ?

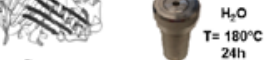
H. Glucose
((Author(s), Corresponding Author(s)*)

Page No. - Page No.

((Title))

Layout 2:

\section{FULL PAPER}

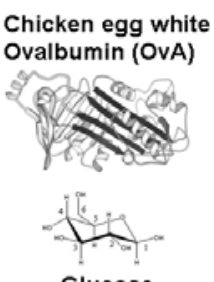

Glucose

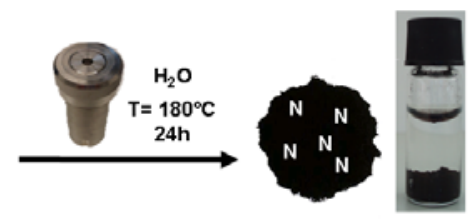

$\mathrm{N}$-doped carbon nanostructures
((Author(s), Corresponding Author(s)*)

Page No. - Page No.

((Title))

In this work, we present a simple and green one-step pathway towards nitrogendoped carbon nanostructures with controlled mesoporosity via hydrothermal treatment of glucose in the presence of model proteins.

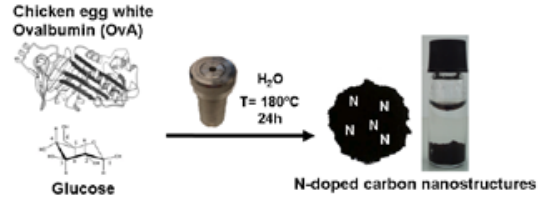

